\title{
A Study of Importance of Solar Calculations for "Two Colored Rainbow System" in Istanbul
}

\author{
Z. $\mathrm{ER}^{*}$ \\ Istanbul Technical University, Faculty of Science and Letters (Maritime Faculty), \\ Physics Engineering Department, 34469 Maslak-Istanbul, Turkey
}

\begin{abstract}
The sun radiation is the largest renewable energy source on the planet which can be used in technology by means of thermal, photovoltaic and concentrated solar power systems. In this study, two types of solar collectors, called the "Two Colored Rainbow System", were used as a source for water heating at the Faculty of Science and Letters, at Istanbul Technical University. The performance of solar water heating system was experimentally investigated. In the experimental study, the temperature of hot water storage tank versus time of the day was investigated. The average daily solar radiation at a location is often sufficient for a basic system analysis. The radiation of sun varies according to the location, date, time and conditions of climate. The change of sun radiation was computed using a determined set of parameters. This study was aimed to offer optimization of design parameters taking into account possible interferences during the operation of the system. Additionally, hourly solar radiation on tilted surfaces is measured in Istanbul. Data of solar radiation intensity were also collected using a standard solarimeter (pyrometer) via a data logger.
\end{abstract}

DOI: 10.12693/APhysPolA.128.B-477

PACS: 96.60.Ub, 96.60.Q, 89.60.-k, 89.30.Cc

\section{Introduction}

For the solar energy systems it is important to know the parameters which are related with the correct values of sun radiation intensity. The radiation of sun varies according to the parameters of location, date, time of day and conditions of climate $[1,2]$. The values of sun radiation can be computed, using determined parameters. If there is a solar energy station built in some place, the sun radiation data for that region has to be known and energy production potential can be calculated. In the developed online system, the sun radiation values that belong to the selected region are calculated and visualized on the world map $[1,3,4]$. In this study, the "Two Colored Rainbow System" is used to trap the solar radiation and to transfer the heat to water for use as the thermal energy.

\section{Materials and methods}

For system design it is essential to know the intensity of solar radiation which is available at a particular location at a given time. The two common methods which characterize solar radiation are the solar radiance (or radiation) and insolation [2]. The instantaneous power density, in units of $\mathrm{kW} / \mathrm{m}^{2}$, is called solar radiance. The solar radiance varies throughout the day between zero at night and maximum value of about $1 \mathrm{~kW} / \mathrm{m}^{2}$ during day time. The solar radiance is strongly dependent on location and local weather parameters [6-8]. These parameters are

*e-mail: erzuh@itu.edu.tr briefly summarized in Table. Solar radiance measurements consist of global and/or direct radiation measurements taken periodically throughout the day. The measurements are taken using either a pyrometer (measuring the global radiation) and/or a pyrheliometer (measuring the direct radiation). This study was realized in February 2013. Hourly global solar radiation on tilted surfaces was measured using a standard solarimeter (pyrometer) via a data logger in Istanbul. An alternative method of measuring solar radiation, which is less accurate and less expensive, is to use a sunshine recorder. This method for this study was realized using calculations with a program written in $\mathrm{C} \#$ language. To estimate the insolation, the cloud-cover data, taken from existing satellite images $[5,6,9,10]$, were taken into account. Finally the on-line results were compared with the results of experiment and calculation in this study.

\section{Results and discussions}

Solar radiation data are available for many locations on an hourly basis. Calculation studies of solar energy systems have generally used these hourly values to estimate long-term annual performance, although solar radiation can exhibit wide variations during an hour. Variation of solar radiation parameters during a month, on a daily basis, could result in inaccurate performance estimation for some types of solar systems. The purpose of this study is to estimate the effect of such parameters on solar energy systems. The parametric evaluation was made by examination of the relations between the frequency distribution and the diffuse fraction. Therefore the usable solar radiation data was compared with the experimental measurements made on tilted surfaces $[6,9,10]$. Figure 1 shows the solar intensity variation during the day, measured on February the 2nd 2013. 
The computational algorithm was developed in $\mathrm{C} \#$ language. Parameters from in Table were calculate in hour-based intervals. Thence the daily, monthly and annual results were obtained and these data were compared with the insolation measurement for a tilted surface. Therefore, the experimental portion of this study was carried out taking into consideration such parameters as day length, the time of sunrise, sunset angle, solar altitude, solar zenith angle, solar azimuth, profile angles, and temperature for February the $2^{\text {nd }} 2013$ at altitude of $41^{\circ} 1^{\prime} 2^{\prime \prime}$.

TABLE

The meteorological parameters that have to be taken into consideration in solar energy studies and calculations for a particular location.

\begin{tabular}{l}
\hline Thermal applications \\
\hline Average daily, monthly or yearly solar insolation \\
Mid-day insolation \\
Open sky insolation (cloudiness $<10 \%)$ \\
Number of shiny days (cloudiness $<10 \%$ ) \\
\hline Solar collectors positioning \\
\hline Tilted surface insolation \\
Diffuse radiation on the horizontal surface \\
Direct normal radiation \\
Insolation in 1 hour intervals \\
Insolation clearness index \\
Solar geometry \\
\hline Sun-noon $($ GMT) \\
Day length \\
Day average of cosines of hourly solar zenith angle \\
Cosines of solar zenith angle at mid time between \\
the sun-rise and the sun-noon \\
Declination \\
Sun-set angle \\
Maximum sun angle with respect to the horizon \\
Hourly sun angle with respect to the horizon \\
Hourly sun azimuth angle \\
\hline Parameters for tilted solar collectors \\
\hline Min. and max. radiation on the tilted surface \\
\hline Temperature \\
\hline Air temperature \\
Daily temperature gap \\
Daily average ground surface temperature: \\
min., max. and amplitude \\
Dew/frost point temperature \\
\hline
\end{tabular}

\section{Conclusions}

This study presents high quality solar measurements suitable for the design of the optimal solar energy system configuration by specifying the parameters of the region. It is necessary to emphasize the following points concerning radiation data calculation and its accuracy:

- more experimental data is required

- more solar calculation models for estimating of radiation values (hourly, daily, monthly etc.) are required,

- user interface of the program should be improved.

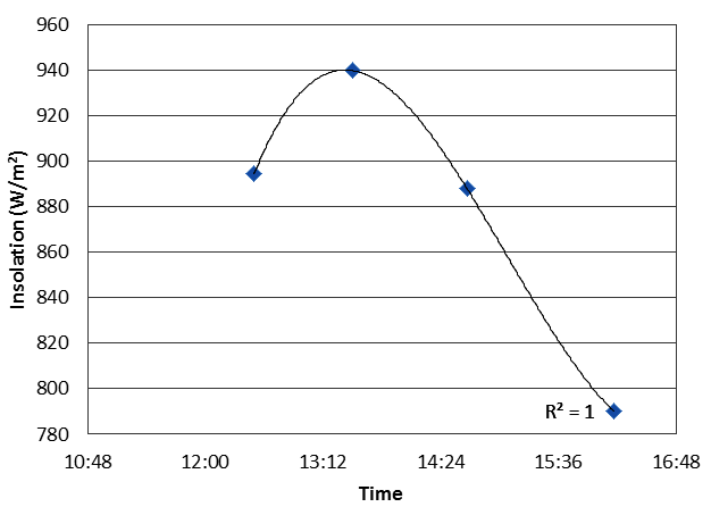

Fig. 1. The diagram of radiation measured by pyranometer at 10:48-16:48 on February the $2^{\text {nd }} 2013$.

All in all the system design pattern should be considered in such a manner that the daily energy consumption rates should be consistent with the annual/biannual simulation data.

\section{References}

[1] 2013 Residential Compliance Manual, Water Heating Requirements Overview - Glossary/Reference, January 2013.

[2] A. Azabany, K. Khan, A. Ahmed, Asian J. Sc. Techn. 5, 423 (2014).

[3] WMO-No. 8, Guide to Meteorological Instruments and Methods of Observation, ISBN 978-92-63-100085, World Meteorological Organization, 2008.

[4] K. Crumbaker, P. McCarty, Introduction to Domestic Solar Hot Water Systems, Fact Sheet No. 10.627, Consumer Series Energy, Colorado State University Extension, 5/11, Revised 8/13, 2013.

[5] C.A. Homola, Solar Domestic Hot Water Heating Systems Design, Installation and Maintenance.

[6] D.R. Myers, Energy 30, 1517 (2005).

[7] M. Paulescu, E. Paulescu, P. Gravila, V. Badescu, Solar Radiation Measurements, Weather Modeling and Forecasting of PV Systems Operation, Green Energy and Technology, Springer-Verlag, London 2013 , p. 358 .

[8] Y.B.L. Hinssen, Comparison of different methods for the determination of sunshine duration, De Bilt, The Netherlands 2006.

[9] G. Major, Radiation and Sunshine Duration Measurements, Comparison of Pyranometers and Electronic Sunshine Duration Recorders of RA VI, Budapest, July February 1984, World Meteorological Organization, March 1984.

[10] E. Vuerich, J.P. Morel, S. Mevel, J. Oliviéri, Updating and Development of Methods for Worldwide Accurate Measurements of Sunshine Duration, Teco-2012, Brussels, Belgium, 16-18 October 2012. 